Original Research Article

\title{
Comparative study of safety and efficacy of pregabalin and gabapentin in management of neuropathic pain associated with chronic lumbar radiculopathy
}

\author{
Huzaif Shaikh, Maaz H. Syed*, Imran N. Khan, Faheem Mubeen
}

Department of Pharmacology, Indian Institute of Medical

Science and Research, Jalna, Maharashtra, India

Received: 09 July 2019

Revised: 03 October 2019

Accepted: 05 October 2019

*Correspondence to:

Dr. Maaz H. Syed,

Email: dr_maaz_syed@

yahoo.com

Copyright: (C) the author(s), publisher and licensee Medip Academy. This is an openaccess article distributed under the terms of the Creative Commons Attribution NonCommercial License, which permits unrestricted noncommercial use, distribution, and reproduction in any medium, provided the original work is properly cited.

\begin{abstract}
Background: Chronic lumbar radiculopathy a clinical condition in which there is back and leg pain associated with sensory, reflex, or motor deficits in the area of nerve root distribution lasting for more than 12 weeks. The prevalence of lumbar radiculopathy has been reported to be $5.3 \%$ in men and $3.7 \%$ in women. Pregabalin and gabapentin, which fit in to a new category of drugs called as alpha-2-delta $(\alpha 2 \delta)$ modulators, have been discovered to be effective in the treatment of neuropathic pain related with multiple conditions. So this study was done to compare safety and efficacy of pregabalin and gabapentin in management of pain associated with chronic lumbar radiculopathy.
\end{abstract}

Methods: This was a randomized two arm comparative prospective study. Total 160 patients were enrolled and randomized equally into 2 groups. Group A patients were given capsule pregabalin $75 \mathrm{mg}$ two times a day orally, Group B patients were given tablet gabapentin $300 \mathrm{mg}$ two times a day. Pain intensity was assessed at the start of study i.e. at baseline ( 0 week), at 6 weeks and at 12 weeks of starting the treatment using numeric pain rating scale.

Results: There was significant reduction in pain at the end of 12 weeks in both the groups $(p<0.0001)$, but there was no significant difference between these two groups. The incidence of adverse effects was also more in group A.

Conclusions: Both the drugs are having comparable efficacy but gabapentin is more tolerable in such cases.

Keywords: Lumbar radiculopathy, Pregabalin, Gabapentin

\section{INTRODUCTION}

Lumbar radiculopathy is a pathological process concerning the lumbar nerve roots that leads to radicular symptoms in the lower extremities. The nerve root pathology is usually from direct neural compression due to various etiological factors like herniated or displaced disc, bony spurs, foraminal stenosis, central stenosis, or hypermobility of a vertebral segment. ${ }^{1}$ Chronic lumbar radiculopathy is defined as a clinical condition in which there is back and leg pain associated with sensory, reflex, or motor deficits in the area of nerve root distribution lasting for more than 12 weeks. $^{2-5}$
The lifetime prevalence of lumbar radiculopathy has been reported to be $5.3 \%$ in men and $3.7 \%$ in women. ${ }^{6}$ Lumbar radiculopathy due to a prolapsed disc resolves spontaneously in $23-48 \%$ of patients, but up to $30 \%$ will still have pronounced symptoms after one year, $20 \%$ will be out of work, and 5-15\% will undergo surgery. ${ }^{7}$ In patients where the primary symptom is leg pain, conservative management like physical therapy, thoughtful use of pain reducing medications and epidural steroid injections, as well as surgical intervention such as lumbar discectomy have been shown to be helpful. ${ }^{8-17}$ Regardless of the introduction of new treatments, the 
management of patients with neuropathic pain remains a challenge. $^{18}$

In this context, the most widely used pharmacological treatments in these patients are non-steroidal antiinflammatory drugs, which are not totally effective in treating pain with a neuropathic element such as the one seen in various radiculopathies. ${ }^{19}$ Such suboptimal treatment of neuropathic pain contributes substantially to the patient disease burden. ${ }^{20-22}$ Although, various therapies are available for neuropathic pain, including antidepressants, opioids, and different antiepileptic drugs, the results of a recent systematic review suggest that, in view of their balance between efficacy and tolerability, pregabalin and gabapentin can be regarded as first line treatments for neuropathic pain. ${ }^{18}$

Pregabalin and gabapentin, which fit in to a new category of drugs called as alpha-2-delta $\left(\alpha_{2} \delta\right)$ modulators, have been discovered to be effective in the treatment of neuropathic pain related with multiple conditions. ${ }^{23-31}$ Given their efficacy in multiple types of neuropathic pain, these drugs are also likely to be effective in neuropathic pain related with nerve root compression, nonetheless no randomized controlled study has revealed their efficacy exclusively in this condition.

\section{METHODS}

The study was conducted in the outpatient department of orthopedics in collaboration with department of pharmacology at MGM'S Medical College and Hospital, Aurangabad. This study was carried out from 11 December 2015 to 18 August 2017. It was a 12 weeks randomized comparative open label single centre two arm prospective study. Patients of either sex and age between 18 to 65 years and diagnosed as cases of chronic lumbar radiculopathy based on symptoms, clinical examination, X-ray and MRI scan of lumbosacral spine and willing to participate in the study and give written and informed consent were included in the study. Written informed consent in patients own vernacular language was obtained. Patients with known hypersensitivity to the study drugs or have taken the study drugs previously within past one month, having history of diabetes, tuberculosis, psychiatric disorders and radiculopathy secondary to tumours were excluded from the study. Patients with impaired immunity, heart, kidney and liver functions were not included in the study. Pregnant and lactating women were also excluded from the study. Total 160 patients were enrolled and randomized equally into 2 groups. Group A patients were given capsule pregabalin $75 \mathrm{mg}$ two times a day orally, Group B patients were given tablet gabapentin $300 \mathrm{mg}$ two times a day. Pain intensity was assessed at the start of study i.e. at baseline ( 0 week), at 6 weeks and at 12 weeks of starting the treatment using numeric pain rating scale (NPRS). Out of 160 patients, 150 patients completed the study. Total 5 subjects ( 3 in group A, 2 in group B) were lost to follow up, who didn't turn up due to severe dizziness and sedation due to study drugs which was confirmed telephonically with the patients. 5 subjects ( 2 in group A, 3 in group B) who developed neurodeficit in lower limbs during the course of study were excluded and referred for immediate surgical intervention. Therefore 75 subjects in each group who completed the 12 weeks study were evaluated.

\section{Statistical analysis}

All the data was entered into Microsoft Excel from case record form for analysis. For comparing quantitative data within the study groups repeated measures ANOVA were used and for comparing quantitative data between the study groups students Unpaired ' $t$ ' test were used. Comparison of qualitative data between the study groups was done using Fisher's exact test. Statistical analysis was performed with the help of the software 'Graph pad Prism 5'. The $\mathrm{p}<0.05$ was considered as statistically significant.

\section{RESULTS}

Out of 160 patients, 150 patients completed the study. Total 5 subjects ( 3 in group A, 2 in group B) were lost to follow up, who didn't turn up due to severe dizziness and sedation due to study drugs which was confirmed telephonically with the patients. 5 subjects ( 2 in group A, 3 in group B) who developed neuro-deficit in lower limbs during the course of study were excluded and referred for immediate surgical intervention. Therefore 75 subjects in each group who completed the 12 weeks study were evaluated. Both the groups were similar in demographic profile at baseline as shown in Table 1. Both the groups showed significant reduction NPRS score at 12 weeks as shown in Table 2. The mean reduction of NPRS pain score in group A from baseline to 12 weeks was 4.3. The mean reduction of NPRS pain score in group B from baseline to 12 weeks was 4.38. In intragroup analysis of both the groups, group A subjects, the mean NPRS pain scores were $8.17 \pm 1.34$ at the start of the study, $6.31 \pm 1.99$ after 6 weeks and3.87 \pm 3.24 at the end of 12 weeks. This signifies that there was a statistically significant decrease in mean pain score $(\mathrm{p}<0.0001)$ at the end of 12 weeks. Similarly, in group B the mean NPRS pain scores were $8.27 \pm 1.18$ at the start of the study, $6.76 \pm 1.56$ at the end of 6 weeks and $3.89 \pm 2.99$ at the end of study i.e. 12 weeks. There was a statistically significant decrease in mean pain score $(p<0.0001)$ at the end of 12 weeks in group B also. But in intergroup comparison the difference in reduction of mean pain scores were not statistically significant at baseline, 6 weeks and 12 weeks as shown in Table 3.During the study various adverse effects were encountered with the use of study drugs. 19 (25.33\%) patients from group A and $7(9.3 \%)$ patients from group B complained of sedation. The $\mathrm{p}$ value came out to be statistically significant $(\mathrm{p}=0.0165) .8(10.7 \%)$ patients from group A and $5(6.7 \%)$ patients from group B complained of dizziness, but the difference between two groups was not significant $(\mathrm{p}=0.5633)$. 
Table 1: Demographic details of patients in group A and group B.

\begin{tabular}{|c|c|c|c|}
\hline Parameter & $\begin{array}{l}\text { Group A } \\
(n=75)\end{array}$ & $\begin{array}{l}\text { Group B } \\
(n=75)\end{array}$ & P value \\
\hline Age in years & $\mathbf{N}(\%)$ & $\mathbf{N}(\%)$ & \\
\hline $21-30$ & $25(33.33 \%)$ & $20(26.66 \%)$ & \multirow{5}{*}{$0.5986^{\dagger}$} \\
\hline $31-40$ & $21(28.0 \%)$ & $27(36.0 \%)$ & \\
\hline $41-50$ & $20(26.66 \%)$ & $22(29.33 \%)$ & \\
\hline $51-60$ & $09(12.0 \%)$ & $06(8.0 \%)$ & \\
\hline Mean \pm SD & $36.79 \pm 10.51$ & $37.64 \pm 9.26$ & \\
\hline \multicolumn{4}{|l|}{ Gender } \\
\hline $\operatorname{Men}(\mathrm{N})$ & 45 & 47 & \multirow{2}{*}{$0.8669^{7}$} \\
\hline Women $(\mathrm{N})$ & 30 & 28 & \\
\hline
\end{tabular}

(n: Numbers; SD: Standard deviation; Values: Mean \pm SD (otherwise mentioned); *: Statistically significant, $\uparrow$ : Using 2-tailed unpaired t-test, + : Using Fisher's exact test.)

Table 2: Comparison of NPRS score in group A and group $B$.

\begin{tabular}{|llll|}
\hline Parameter & $\begin{array}{l}\text { Group A } \\
(\text { Mean } \pm \text { SD) }\end{array}$ & $\begin{array}{l}\text { Group B } \\
\text { (Mean } \pm \text { SD) }\end{array}$ & \begin{tabular}{c} 
P value inter $_{\text {group }^{\dagger}}$ \\
\hline Mean NPRS score
\end{tabular} \\
\hline Baseline & $8.17 \pm 1.34$ & $8.27 \pm 1.18$ & 0.6511 \\
\hline 6 weeks & $6.31 \pm 1.99$ & $6.76 \pm 1.56$ & 0.1228 \\
\hline 12 weeks & $3.87 \pm 3.24$ & $3.89 \pm 2.99$ & 0.9583 \\
\hline P value intragroup & $<0.0001^{\S}$ & $<0.0001^{*}$ & \\
\hline
\end{tabular}

(n: Numbers; Values: Mean \pm SD (otherwise mentioned); *: Statistically significant, $\uparrow:$ Using 2-tailed unpaired t-test, $\S$ : Repeated measure ANOVA.)

Table 3: Adverse drug reactions in group A and group B.

\begin{tabular}{|llll|}
\hline Adverse effect & $\begin{array}{l}\text { Group A } \\
(\mathbf{n = 7 5 )}\end{array}$ & $\begin{array}{l}\text { Group B } \\
(\mathbf{n = 7 5 )}\end{array}$ & $\begin{array}{l}\text { P value inter } \\
\text { group }\end{array}$ \\
\hline Sedation & 19 & 7 & $0.0165^{*}$ \\
\hline Dizziness & 8 & 0 & 0.5633 \\
\hline Dry mouth & 0 & 0 & - \\
\hline Constipation & 0 & 5 & - \\
\hline
\end{tabular}

(n: Numbers; *: Statistically significant; +: Using Fisher's exact test.)

\section{DISCUSSION}

Chronic lumbar radiculopathy is a painful condition of back and leg associated with sensory, reflex, or motor deficits in the area of nerve root distribution lasting for more than 12 weeks. The conservative management mainly consists of drugs like NSAIDS, corticosteroids, pregabalin, gabapentin, tricyclic antidepressants, duloxetine, epidural steroids etc. Pregabalin and gabapentin are important drugs in treating all types of neuropathic pain including radiculopathy. Pregabalin is a structural analog of gamma-amino butyric acid (GABA) and it selectively binds the $\alpha_{2}-\delta$ subunit, of voltagedependent calcium channels, and which possesses analgesic, anxiolytic, and antiepileptic properties. $^{32}$ Gabapentin having agonistic action on a subset of $\mathrm{GABA}_{\mathrm{B}}$ receptors which negatively regulates the $\alpha 2 \delta-1$ subunit of voltage gated $\mathrm{Ca}^{2+}$ channels, activate inwardly rectifying $\mathrm{K}^{+}$channels, blocks $\mathrm{Ca}^{2+}$ and $\mathrm{Na}^{+}$channels and open $\mathrm{K}^{+}$channels which leads to inhibition of the abnormal activity and hyper-excitability of sensory neurons, thereby reducing pain.

In our study, we found that at the end of 12 weeks, pregabalin was quiet efficient in reducing the pain of chronic lumbar radiculopathy. The mean pain score in patients treated with pregabalin reduced significantly to 3.87 from 8.17. This finding was similar to the study conducted by Baron et al. ${ }^{33}$ Gabapentin also reduced chronic lumbar radiculopathy pain significantly at the end of 12 weeks. In patients treated with gabapentin, the mean pain score reduced significantly to 3.89 from 8.27. This finding was similar to the study conducted by Kasimcan et al. ${ }^{34}$ Pain reduction in patients treated with pregabalin was $52.63 \%$, and with gabapentin it was $52.96 \%$ at the end of 12 weeks. Hence, pregabalin showed comparable pain reduction as compare to gabapentin $[52.63 \%$ vs. $52.96 \%$ ] at the end of 12 weeks study. When we did intergroup comparison between group $\mathrm{A}$ and $\mathrm{B}$, the difference in reduction of mean pain scores were not 
statistically significant at baseline, 6 weeks and 12 weeks. Tzellos et al reported that results from randomized trials support the superior efficacy of pregabalin when compared to gabapentin, which is in contrast to our study. ${ }^{35}$ Moreover, the incidence of adverse effects like sedation and dizziness was more in subjects treated with pregabalin as compared to those treated with gabapentin.

The limitation of our study was that it was a single centre study and subjects were not followed up after 12 weeks which could have been helpful in finding out long term implications and effects of the study drugs. We could also have included other available drugs for chronic lumbar radiculopathy as additional comparative groups in the study.

\section{CONCLUSION}

Through this study we conclude that both pregabalin and gabapentin are equally efficacious in management of pain associated with chronic lumbar radiculopathy but, superior tolerability of gabapentin by the patients makes it a better option as compared to pregabalin.

Funding: No funding sources

Conflict of interest: None declared

Ethical approval: The study was approved by the Institutional Ethics Committee

\section{REFERENCES}

1. Dumitru D, Amato AA, Zwarts M. Electrodiagnostic medicine. 2nd ed. Philadelphia, PA; Hanley and Belfus Inc.; 2002

2. Price C, Arden N, Coglan L, Rogers P. Costeffectiveness and safety of epidural steroids in the management of sciatica. Health Technol Assess. 2005;9:1-58

3. Waddell G. The back pain revolution. 2nd ed. Churchill Livingstone, 2004.

4. Fairbank JC. Sciatica: an archaic term. BMJ. 2007;335:112.

5. Koes BW, van Tulder MW, Peul WC. Diagnosis and treatment of sciatica. BMJ. 2007;334:1313-7.

6. Konstantinou K, Dunn KM. Sciatica: review of epidemiological studies and prevalence estimates. Spine. 2008;33:2464-72.

7. Karppinen J, Ohinmaa A, Malmivaara A, Kurunlahti M, Kyllönen E, Pienimäki T, et al. Cost effectiveness of peri-radicular infiltration for sciatica: subgroup analysis of a randomized controlled trial. Spine. 2001;26:2587-95.

8. Anderson PA, McCormick PC, Angevine PD. Randomized controlled trials of the treatment of lumbar disk herniation: 1983-2007. J Am Acad Orthop Surg. 2008;16:566-73.

9. Atlas SJ, Keller RB, Wu YA, Deyo RA, Singer DE. Long-term outcomes of surgical and nonsurgical management of sciatica secondary to a lumbar disc herniation: 10 year results from the Maine Lumbar Spine Study. Spine. 2005;30:927-35.

10. Bono CM, Wisneski R, Garfin SR. Lumbar disc herniations. In: Herkowitz HN, Garfin SR, Eismont FJ, Bell GR, Balderston RA, editors. The Spine. 5th ed. Philadelphia, PA: Saunders; 2006.

11. Buttermann GR. Treatment of lumbar disc herniation: Epidural steroid injection compared with discectomy. J Bone Joint Surg Am. 2004;86:670-9.

12. Carragee E. Surgical treatment of disk disorders. JAMA. 2006; 296:2485-2487.

13. Guilfoyle MR, Ganesan D, Seeley H, Laing RJ. Prospective study of outcomes in lumbar discectomy. Br J Neurosurg. 2007;21:389-95.

14. Majlesi J, Togay H, Unalan H, Toprak S. The sensitivity and specificity of the slump and the straight leg raising tests in patients with lumbar disc herniation. J Clin Rheumatol. 2008;14:87-91.

15. Peul WC, van Houwelingen HC, van den Hout WB, Brand R, Eekhof JA, Tans JT, et al. Surgery versus prolonged conservative treatment for sciatica. N Engl J Med. 2007;356:2245-56.

16. Peul WC, van den Hout WB, Brand R, Thomeer RT, Koes BW; Leiden-The Hague Spine Intervention Prognostic Study Group. Prolonged conservative care versus early surgery in patients with sciatica caused by lumbar disc herniation: Two year results of a randomised controlled trial. BMJ. 2008;336:1355-8.

17. Weinstein JN, Lurie JD, Tosteson TD, Tosteson AN, Blood EA, Abdu WA, et al. Surgical versus nonoperative treatment for lumbar disc herniation: Four year results for the Spine Patient Outcomes Research Trial (SPORT). Spine. 2008;33:2789-800.

18. Finnerup NB, Otto M, McQuay HJ, Jensen TS, Sindrup SH. Algorithm for neuropathic pain treatment: an evidence based proposal. Pain. 2005;118(3):289-305.

19. Harden N, Cohen M. Unmet needs in the management of neuropathic pain. J Pain Symptom Manage. 2003;25(5 Suppl):S12-S17.

20. Tolle T, Xu X, Sadosky AB. Painful diabetic neuropathy: a cross-sectional survey of health state impairment and treatment patterns. J Diabetes Complications. 2006;20(1):26-33.

21. Tolle T, Dukes E, Sadosky A. Patient burden of trigeminal neuralgia: results from a cross-sectional survey of health state impairment and treatment patterns in six European countries. Pain Pract. 2006;6(3):153-60.

22. Seventer R, Sadosky A, Lucero M, Dukes E. A crosssectional survey of health state impairment and treatment patterns in patients with postherpetic neuralgia. Age Ageing. 2006;35(2):132-7.

23. Lesser H, Sharma U, LaMoreaux L, Poole RM. Pregabalin relieves symptoms of painful diabetic neuropathy: A randomized controlled trial. Neurology. 2004;63:2104-10.

24. Rosenstock J, Tuchman M, LaMoreaux L, Sharma U. Pregabalin for the treatment of painful diabetic 
peripheral neuropathy: A double-blind, placebocontrolled trial. Pain. 2004;110:628-38.

25. Richter RW, Portenoy R, Sharma U, LaMoreaux L, Bockbrader H, Knapp LE. Relief of painful diabetic peripheral neuropathy with pregabalin: A randomized, placebo-controlled trial. J Pain. 2005;6:253.

26. Freynhagen R, Strojek K, Griesing T, Whalen E, Balkenohl M. Efficacy of pregabalin in neuropathic pain evaluated in a 12-week, randomised, doubleblind, multicentre, placebo-controlled trial of flexible- and fixed-dose regimens. Pain. 2005; 115:254-63.

27. Dworkin RH, Corbin AE, Young JP, Jr, Sharma U, LaMoreaux L, Bockbrader H, et al. Pregabalin for the treatment of postherpetic neuralgia: A randomized, placebo-controlled trial. Neurology. 2003;60:127483.

28. Sabatowski R, Gálvez R, Cherry DA, Jacquot F, Vincent E, Maisonobe $\mathrm{P}$, et al. Pregabalin reduces pain and improves sleep and mood disturbances in patients with post-herpetic neuralgia: Results of a randomised, placebo-controlled clinical trial. Pain. 2004;109:26-35.

29. Van Seventer R, Feister HA, Young JP, Jr, Stoker M, Versavel M, Rigaudy L. Efficacy and tolerability of twice-daily pregabalin for treating pain and related sleep interference in postherpetic neuralgia: A 13week, randomized trial. Curr Med Res Opin. 2006;22:375-84.

30. Siddal P, Cousins M, Otte A, Phillips K, Griesing T. Pregabalin safely and efficaciously treats chronic central neuropathic pain after spinal cord injury. J Pain. 2005;6:S25.
31. Caraceni A, Zecca E, Bonezzi C, Arcuri E, Tur R, Maltoni M, et al. Gabapentin for neuropathic cancer pain: A randomized controlled trial from gabapentin cancer pain study group. J Clin Oncol. 2004;22:290917.

32. Tassone DM, Boyce E, Guyer J, Nuzum D. Pregabalin: a novel gamma-aminobutyric acid analogue in the treatment of neuropathic pain, partialonset seizures, and anxiety disorders. Clin Ther. 2007;29(1):26-48.

33. Baron R, Freynhagen R, Tolle TR, Cloutier C, Leon $\mathrm{T}$, Murphy TK, et al. The efficacy and safety of pregabalin in the treatment of neuropathic pain associated with chronic lumbosacral radiculopathy. Pain. 2010;150(3):420-7.

34. Kasimcan O, Kaptan H. Efficacy of gabapentin for radiculopathy caused by lumbar spinal stenosis and lumbar disk hernia. Neurologia medico-chirurgica. 2010;50(12):1070-3.

35. Tzellos TG, Papazisis G, Amaniti E, Kouvelas D. Efficacy of pregabalin and gabapentin for neuropathic pain in spinal-cord injury: an evidencebased evaluation of the literature. Eur J Clin Pharmacol. 2008;64(9):851-8.

Cite this article as: Shaikh H, Syed MH, Khan IN, Mubeen F. Comparative study of safety and efficacy of pregabalin and gabapentin in management of neuropathic pain associated with chronic lumbar radiculopathy. Int J Basic Clin Pharmacol 2019;8:2480-4. 